\title{
B CHROMOSOME SELECTION AND FITNESS IN RYE
}

\author{
S. B. TEOH* and R. N. JONES $\uparrow$ \\ * Department of Genetics and Cellular Biology, University of Malaya, \\ Kuala Lumpur 22-11, Malaysia; and †Department of Agricultural Botany, \\ University College of Wales, Aberystwyth, Wales, U.K.
}

Received 28.xi.77

\begin{abstract}
Summary
Two rye populations with a B chromosome polymorphism were subject to a range of environmental stress conditions, by varying the sowing density, to assess the relative fitness of individuals with and without $B$ chromosomes. In the Experimental population, characterised by a wide range and high frequency of $\mathrm{B}$ numbers, the $\mathrm{B}$ chromosome individuals were found to compete and survive less well than their $0 \mathrm{~B}$ counterparts throughout the range of densities used. Much of the reduced fitness in this population was due to the presence of odd-numbered and high-numbered B combinations. Progenies derived from plants surviving to maturity, however, were found to have significantly higher B frequencies, and a greater range of B numbers, than their parent plants. The Korean population, with a much lower B frequency, and composed mainly of $0 \mathrm{~B}$ and $2 \mathrm{~B}$ types, showed a more complex relationship between $B$ frequency and plant density. At low densities plants with Bs had a selective advantage over those without. They also responded more favourably, in terms of survival, at very high rather than at intermediate densities. In this variety there were no significant differences in mean $B$ frequency between the standard population from which the seed sample originated, the parent plants subjected to density stress and suffering a high mortality rate, and the seed progenies derived from these parents.
\end{abstract}

\section{INTRODUCTION}

The chromosome number of rye (Secale cereale) is $2 n=2 x=14$. In many areas of the world, particularly where "primitive" strains are grown, which have not been subjected to high selection for fertility and uniformity, a $\mathrm{B}$ chromosome polymorphism exists giving chromosome numbers over the range $2 n=2 x=14+0-8$ Bs. The polymorphism is widespread. B chromosomes were found in all 32 of the Korean populations studied by Lee and Min (1965); in all 25 of the Yugoslavian populations sampled by Zečević and Paunović (1967) and they are also present in high frequencies in several other populations sampled in Iran, Turkey and Japan. The frequency of plants with B chromosomes varied from 2-73 per cent, and 10-55 per cent for the Korean and Yugoslavian populations respectively. In Japanese populations up to 97 per cent of plants may carry one or more Bs (Kishikawa, 1965).

These large differences in B frequency, between different populations, strongly suggest that the Bs are of adaptive significance and that they confer varying degrees of fitness upon the populations in response to differing environmental circumstances. There are many studies which show that the rate of transmission and accumulation of these extra chromosomes are under genetical control affecting the pairing of the Bs at meiosis and their capacity to undergo non-disjunction in the gametophytes. Correlations of 
B frequency and distribution with environmental variables, taken in conjunction with the transmission data, clearly indicate that the interaction between genetic and environmental factors determines the final equilibrium frequencies in individual populations. Notwithstanding this generalisation it has proved remarkably difficult to demonstrate any superior physiological or reproductive fitness attributable to the individuals carrying $\mathrm{Bs}$, over those which do not, and this difficulty extends to many other species besides rye (see Jones, 1975). Contrariwise it is a simple matter to list a whole range of disadvantageous, or at best neutral, effects of $\mathrm{B}$ chromosomes on all aspects of the growth, development, and reproductive potential of individuals of the species which carry them.

A novel type of experimental system, which involves growing plants at variable densities in plastic multipots, has recently been used to some effect in exploring this question of fitness and B chromosomes (Rees and Hutchinson, 1973). Selection is confined to one variable, namely density, and the severity of the stress applied can be readily adjusted right up to the limit of endurance of the plants involved. Multipot experiments with Lolium perenne have convincingly demonstrated an increased fitness of plants with B chromosomes, over those without (Teoh, Rees and Hutchinson, 1976). In a Japanese variety of B chromosome rye the opposite effect was found and the plus B individuals were at a disadvantage as the plant densities were raised (Hutchinson, 1975). The present analysis considers the response of two further, and two different, rye populations to density stress, and in addition includes data on the $B$ frequencies among progeny plants descended from the surviving parents. Rye is an annual species and the effectiveness of selection within one generation is more meaningful when its consequences to the progenies are also taken into account.

\section{MAterials AND MEthods}

(i) Materials

Two populations of rye with contrasting origins were used. The first population referred to as "Experimental rye", is of hybrid origin in which the parents were Secale cereale var. Stälrag and $S$. vavilovii. Initial crosses between the two species were made in 1961 and since then the stocks have been multiplied by open pollination through successive generations. The detailed background of this population has been described by Jones and Rees $(1967,1968)$. It is worth while pointing out that the Bs in the hybrid population were derived from $S$. vavilovii only. The seeds used in this investigation were obtained from plants grown and harvested in 1970 .

The second rye population originates from a sample of seeds, obtained from $\mathrm{Dr}$ W. J. Lee (Seoul National University, Korea), belonging to a naturally occurring strain called "Paldang No. 1". This sample of seeds was grown and harvested in 1969 and constitutes the second rye population.

For reference throughout this investigation, the seeds which make up each population will be referred to as the "standard population".

(ii) Methods

\section{(a) Chromosome counts}

Rye seeds were germinated on moist filter paper in petri dishes at $25^{\circ} \mathrm{C}$ in an oven. Roots, $1-2 \mathrm{~cm}$ long, were cut and pretreated in 0.2 per cent 
colchicine for 3 hours. The roots were fixed in $3: 1$ alcohol acetic acid for half an hour, hydrolysed in $1 \mathrm{~N} \mathrm{HCl}$ for 10 minutes at $60^{\circ} \mathrm{C}$, stained in Feulgen and finally, squashed in acetocarmine. The presence or absence of B chromosomes of the standard type was recorded.

\section{(b) Density experiments}

The experiment was set up in a cold greenhouse. Seeds from each standard population were sown according to the desired densities in John Innes No. 2 potting compost in plastic multipot trays. Each tray consists of 24 small pots, each having a diameter of $6.5 \mathrm{~cm}$. The densities sown were $5,10,25,50,75,100$ and 150 seeds per pot. There were two replicates (trays) for each density. The trays were randomised and put in the same greenhouse to ensure that both populations received the same environmental conditions throughout the duration of the experiment.

\section{(c) Germination}

The numbers of seeds germinated at the different densities were recorded at daily intervals from the 5 th to the 10th day after sowing. No further germination took place after the 10th day.

\section{(d) Fixing of flowering heads}

As the plants matured heads were removed and fixed in Carnoy's solution to which ferric chloride had been added and stored at $0-5^{\circ} \mathrm{C}$ before squash preparations were made. Altogether 30 to 40 heads were removed from each replicate in each density.

\section{(e) Scoring of flowering heads}

Prior to scoring, all the fixed heads from each replicate in each density were mixed in a container. Individual heads were then picked out at random. The anthers were dissected out and squashed in acetocarmine. The numbers of Bs were determined at late diakinesis or metaphase I.

\section{(f) Progeny}

Before anthesis, the plants in each tray were bagged and allowed to cross-pollinate. The bags were shaken twice daily. Before harvesting, the bags were removed to allow the heads to dry completely. Seeds from each replicate per density were pooled together and, subsequently, germinated in petri dishes and scored for their B chromosome content.

\section{(g) Survival rate}

The number of plants surviving to maturity in each pot was recorded for each density when the heads were ready for harvesting.

\section{REsults}

\section{(i) The standard populations}

The data for the distributions of $\mathrm{B}$ chromosomes in the two standard populations of Experimental and Korean rye are given in tables 1 and 2 respectively. Two important differences characterise the two populations:

(i) The proportion of plants containing Bs in the Experimental variety is about three times more than that in the Korean. 
TABLE 1

$B$ chromosome distribution among survivors of the Experimental rye density experiment, together with the data on percentage survival, mean $B$ per plant and chi-square analysis for comparison with distribution of $B$ chromosomes in the standard population

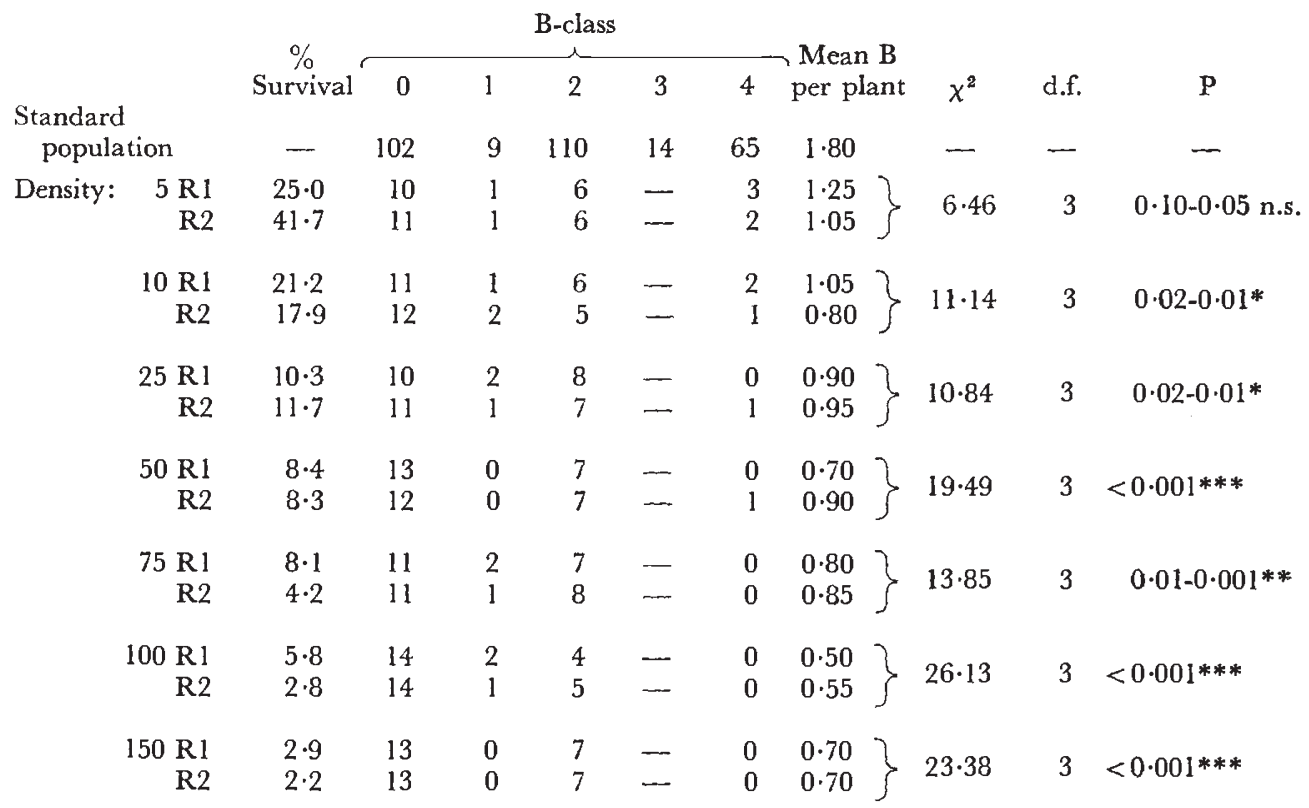

TABLE 2

$B$ chromosome distribution among survivors of the Korean rye density experiment, together with the data on percentage survival, mean $B$ per plant and chi-square analysis for comparison with distribution of $B$ chromosomes in the standard population

\begin{tabular}{|c|c|c|c|c|c|c|c|c|c|c|c|}
\hline \multirow{3}{*}{\multicolumn{2}{|c|}{$\begin{array}{l}\text { Standard } \\
\text { population }\end{array}$}} & \multicolumn{6}{|c|}{ B-class } & \multirow[b]{2}{*}{$\begin{array}{l}\text { Mean B } \\
\text { per plant }\end{array}$} & \multirow[b]{2}{*}{$x^{2}$} & \multirow[b]{2}{*}{ d.f. } & \multirow[b]{2}{*}{ p } \\
\hline & & $\begin{array}{c}\% \\
\text { Survival }\end{array}$ & 0 & 1 & 2 & 3 & 4 & & & & \\
\hline & & - & 170 & - & 42 & - & 7 & 0.50 & - & - & - \\
\hline Density: & $\begin{array}{r}5 \mathrm{R} 1 \\
\mathrm{R} 2\end{array}$ & $\begin{array}{l}50 \cdot 8 \\
51 \cdot 7\end{array}$ & $\begin{array}{l}16 \\
17\end{array}$ & - & $\begin{array}{l}9 \\
8\end{array}$ & - & $\begin{array}{l}0 \\
0\end{array}$ & $\begin{array}{l}0 \cdot 72 \\
0 \cdot 64\end{array}$ & $8 \cdot 17$ & 2 & $0 \cdot 02-0.01 *$ \\
\hline & $\begin{array}{r}10 \mathrm{R} 1 \\
\mathrm{R} 2\end{array}$ & $\begin{array}{l}40 \cdot 8 \\
27 \cdot 5\end{array}$ & $\begin{array}{l}20 \\
19\end{array}$ & - & $\begin{array}{l}5 \\
6\end{array}$ & - & $\begin{array}{l}0 \\
0\end{array}$ & $\begin{array}{l}0 \cdot 40 \\
0 \cdot 48\end{array}$ & 1.80 & 2 & $0 \cdot 20-0 \cdot 10$ n.s. \\
\hline & $\begin{array}{r}25 \mathrm{R} 1 \\
\mathrm{R} 2\end{array}$ & $\begin{array}{l}16 \cdot 8 \\
27 \cdot 8\end{array}$ & $\begin{array}{l}22 \\
22\end{array}$ & - & $\begin{array}{l}3 \\
3\end{array}$ & I & $\begin{array}{l}0 \\
0\end{array}$ & $\begin{array}{l}0 \cdot 24 \\
0.24\end{array}$ & $3 \cdot 65$ & 2 & $0 \cdot 20-0 \cdot 10$ n.s. \\
\hline & $\begin{array}{r}50 \mathrm{R} 1 \\
\mathrm{R} 2\end{array}$ & $\begin{array}{l}19 \cdot 0 \\
14 \cdot 3\end{array}$ & $\begin{array}{l}23 \\
24\end{array}$ & - & $\begin{array}{l}2 \\
1\end{array}$ & - & $\begin{array}{l}0 \\
0\end{array}$ & $\begin{array}{l}0 \cdot 16 \\
0.08\end{array}$ & $7 \cdot 84$ & 2 & $0.02-0.01 *$ \\
\hline & $\begin{array}{r}75 \mathrm{R} 1 \\
\mathrm{R} 2\end{array}$ & $\begin{array}{l}11.8 \\
12.8\end{array}$ & $\begin{array}{l}22 \\
21\end{array}$ & - & $\begin{array}{l}2 \\
4\end{array}$ & - & $\begin{array}{l}1 \\
0\end{array}$ & $\begin{array}{l}0 \cdot 32 \\
0 \cdot 32\end{array}$ & $2 \cdot 04$ & 2 & $0 \cdot 50-0 \cdot 30 \mathrm{n.s}$ \\
\hline & $\begin{array}{r}100 \mathrm{R} 1 \\
\mathrm{R} 2\end{array}$ & $\begin{array}{l}5 \cdot 9 \\
6 \cdot 8\end{array}$ & $\begin{array}{l}21 \\
20\end{array}$ & - & $\begin{array}{l}4 \\
5\end{array}$ & - & $\begin{array}{l}0 \\
0\end{array}$ & $\begin{array}{l}0 \cdot 32 \\
0 \cdot 40\end{array}$ & 1.77 & 2 & $0 \cdot 50-0 \cdot 30$ n.s. \\
\hline & $\begin{array}{r}150 \mathrm{R} 1 \\
\mathrm{R} 2\end{array}$ & $\begin{array}{l}3 \cdot 8 \\
2 \cdot 7\end{array}$ & $\begin{array}{l}21 \\
21\end{array}$ & - & $\begin{array}{l}4 \\
3\end{array}$ & - & 0 & $\left.\begin{array}{l}0.32 \\
0.40\end{array}\right\}$ & $1 \cdot 19$ & 2 & $0 \cdot 70-0 \cdot 50$ n.s. \\
\hline
\end{tabular}


(ii) In Korean rye, plants with odd numbers of Bs are conspicuously absent. However, in Experimental rye, odd and even numbers are present but even numbers of Bs still constitute by far the majority of $\mathrm{B}$ plants. The ratio of $2 \mathrm{~B}$ to $4 \mathrm{~B}$ plants is 6.0 and 1.7 for the Korean and Experimental rye respectively.

\section{(ii) Germination}

The data for the final germination percentages, 10 days after sowing, are given in table 3 . It was not possible, of course, to categorise the $B$ types according to their germination potential, but the data do show quite convincingly that there is considerable selection pressure and mortality at this critical stage in the developmental process. Regression analyses of

\section{TABLE 3}

Final germination percentage, 10 days after sowing, in the Experimental and Korean rye density experiment

\begin{tabular}{cccccc} 
& \multicolumn{2}{c}{ Experimental } & \multicolumn{2}{c}{ Korean } \\
\cline { 2 - 6 } Density & $\%$ & Angles & & Angles \\
5 & $44 \cdot 0$ & $41 \cdot 55$ & & $61 \cdot 0$ & $51 \cdot 35$ \\
10 & $42 \cdot 0$ & $40 \cdot 40$ & $55 \cdot 0$ & $47 \cdot 87$ \\
25 & $34 \cdot 4$ & $35 \cdot 91$ & $50 \cdot 4$ & $45 \cdot 23$ \\
50 & $30 \cdot 7$ & $33 \cdot 65$ & $41 \cdot 1$ & $39 \cdot 87$ \\
75 & $27 \cdot 1$ & $31 \cdot 37$ & $39 \cdot 0$ & $38 \cdot 65$ \\
100 & $20 \cdot 5$ & $26 \cdot 92$ & $36 \cdot 0$ & $36 \cdot 87$ \\
150 & $17 \cdot 1$ & 24.43 & 33.5 & $35 \cdot 37$
\end{tabular}

variance show that the final percentage germination (angular transformation, as percentages do not fit a normal distribution) against density, in each variety, as highly significant $(P<0.001$ and $P=0.05-0.01$ for the Experimental and Korean populations respectively). A joint regression analysis of variance shows that the two populations did not differ significantly in their rates of decrease of germination, and that the mean percentage of germinated seedlings was higher in the Korean variety $(\mathrm{P}<0.001)$.

\section{(iii) Density and B frequency}

The distribution of $B$ chromosome types among the surviving plants at each density, is shown in tables 1 and 2. As expected in the Korean variety (table 2), the odd numbered combinations of Bs are absent. Plants with 4 Bs seem to have been almost completely eliminated while those with 2 Bs have survived much better. It is also clear that the proportion of $2 \mathrm{~B}$ plants in this variety decreases up to density 50 but then increases and remains relatively stable in the higher ones. Similarly, in the Experimental variety (table 1) plants with odd $\mathrm{B}$ numbers, or more than $2 \mathrm{Bs}$, seem to show particular vulnerability to increasing sowing densities. Thus plants with $3 \mathrm{Bs}$ are absent in all densities even though they initially made up 4.5 per cent of the standard population. The $4 \mathrm{~B}$ plants diminish numerically as density increases but there are only slight variations in the $1 \mathrm{~B}$ and $2 \mathrm{~B}$ classes. Clearly, the two rye varieties not only differ in their B chromosome composition but also in their response to changing densities. The differences 
or similarities in behaviour of the two varieties are considered in more detail below.

(a) Experimental rye. The calculated mean B frequency for each density in each replicate is presented in table 1 . An analysis of variance shows that there are no significant differences between replicates but that the mean $B$ frequencies do differ significantly $(P=0.05-0.01)$ at different densities. Detailed Q-test comparisons (see Snedecor and Cochran, 1967, p. 271) reveal that at the 5 per cent level only the densities 5 and 100 differ from

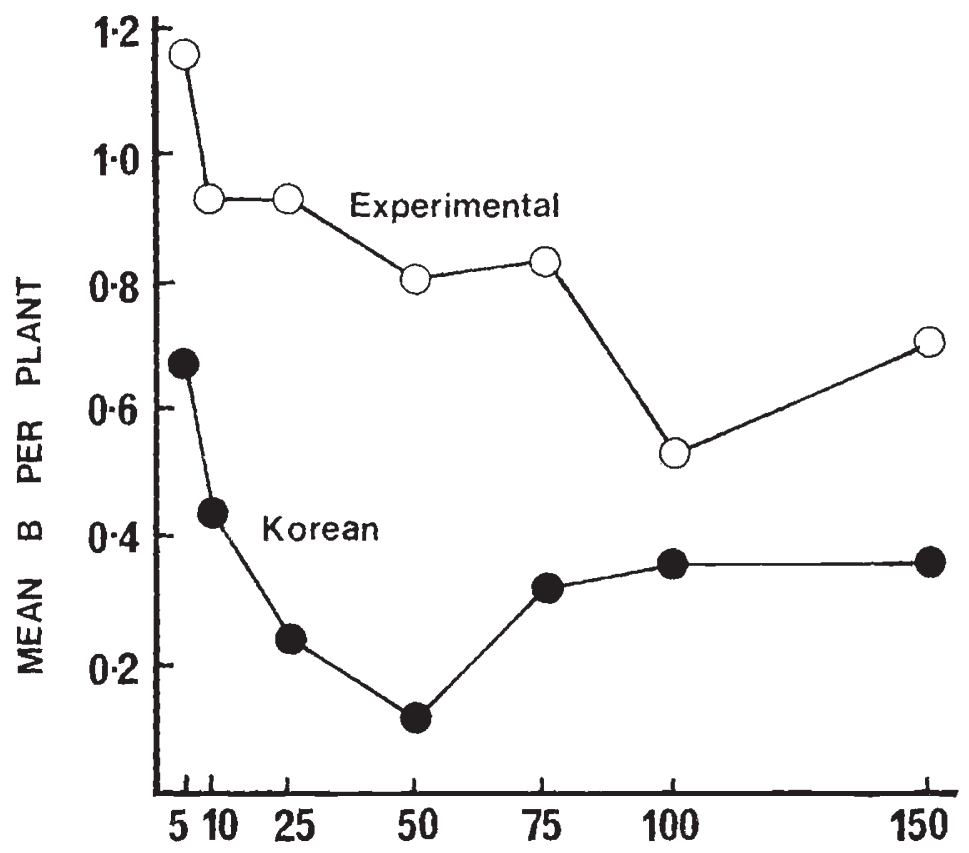

\section{DENSITY}

Frg. 1.-Mean Bs per plant plotted against sowing density in Experimental and Korean rye (pooled over replicates).

each other. Nevertheless, when we plot the mean B frequencies against sowing density (fig. 1), there is evidently a decreasing trend in B frequencies associated with increasing density. A significant regression analysis of variance confirms this trend $(P=<0 \cdot 01)$. These results indicate that the ability of plants with $\mathrm{Bs}$ to compete and survive against $0 \mathrm{~B}$ plants is progressively diminished with increasing density.

(b) Korean rye. The data in table 2 and fig. 1 shows that the B chromosome distribution according to density in Korean rye differs from that of the Experimental material. While there is a steady decline in B frequency in the Experimental variety, the response of the Korean B plants is rather more complex. There is a steep fall in the "low" densities (5-50) but then a recovery in the "high" ones (50-150) which then remains at a consistent level. 
An analysis of variance shows that the differences between densities are highly significant $(P=<0 \cdot 001)$. Q-tests at the 5 per cent level show that: (i) density 5 differed from all other densities, (ii) density 10 differed from density 50 and, (iii) density 50 differed from the higher densities of 100 and 150. This analysis confirms that the pattern of $B$ distribution differs between the "low" and "high" densities mentioned above. From these results it is clear that the ability of plants with $\mathrm{Bs}_{\mathrm{s}}$ to compete and survive compared to those without deteriorates rapidly in the "low" density conditions, except for density 5, but where extremely adverse conditions are encountered, such as those found in the highest densities, the B plants seem to perform much better.

\section{(iii) Mortality and $B$ frequency}

One would expect that as the sowing density increases the mortality rate would rise. This trend was observed in both populations (fig. 2) where a mortality of over 97 per cent was recorded for the highest density. Regression analyses of variance of percentage survival (in angles) against sowing density for both populations confirm the decreasing trend to be highly significant $(\mathrm{P}<0.001)$. A joint regression analysis shows that the rates of

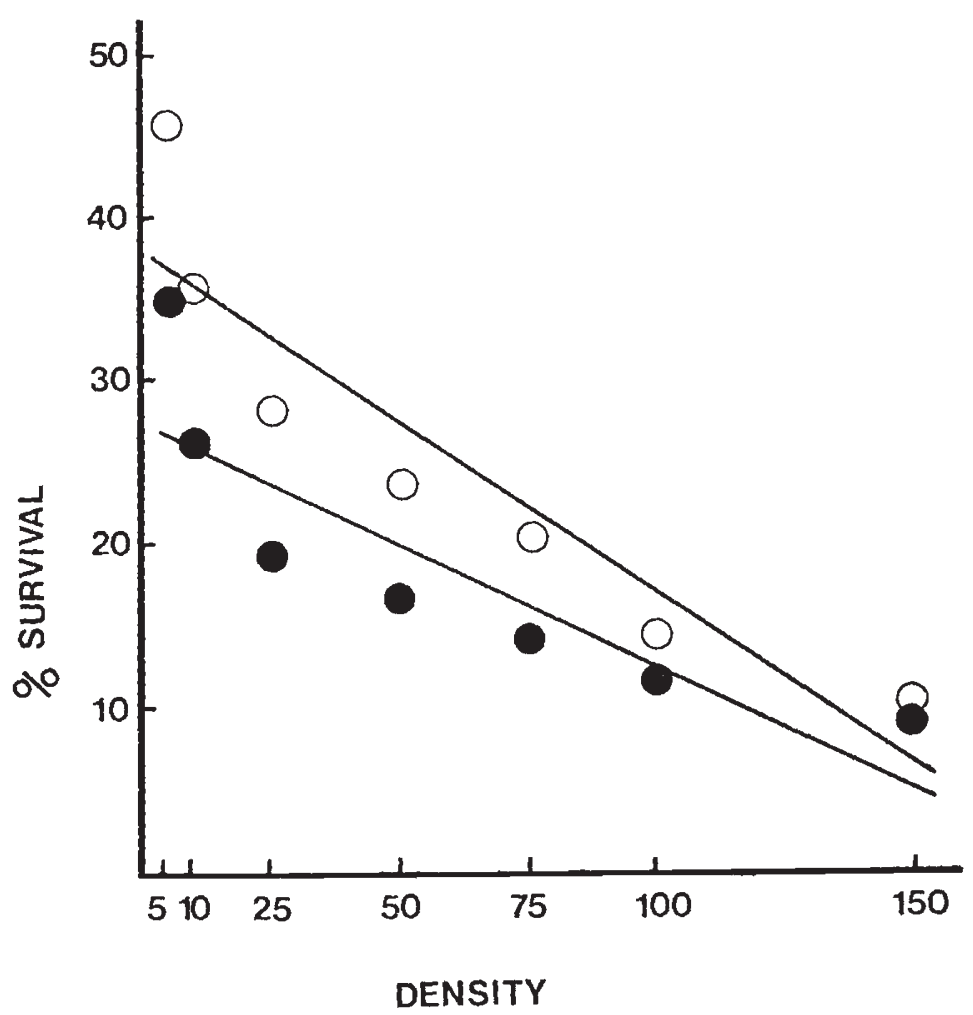

Fig. 2.--Percentage survival (transformed to angles) against sowing density in Experimental and Korean $\mathrm{O}-\mathrm{O}$ rye, pooled over replicates. 
mortality in both varieties are similar, but the mean percentage survival is significantly higher in the Korean variety $(P=0 \cdot 01-0.001)$, see also tables 1 and 2.

\section{(iv) Comparisons with the standard populations}

We have shown that there is a range of distribution of $\mathrm{B}$ chromosomes in response to varying densities in both varieties. However, these resulting distributions achieve greater significance when considered in relation to those in the standard populations from which they were initially derived. This can be done by comparing the $\mathrm{B}$ chromosome distribution in each density with the standard populations by means of chi-square analyses (tables 1 and 2). In making these analyses the data for each density are summed over replicates since they were shown earlier not to be significantly different. In Experimental rye the data for the $1 \mathrm{~B}$ and $3 \mathrm{~B}$ distributions have been pooled. The analyses show that for the Experimental rye there are significant deviations for all densities, except the lowest one (5), and that differential mortality has affected plants with Bs more severely than those without. In the Korean rye variety, significant deviations are found for densities 5 and 50 only. Thus, at the lowest density, there is an excess of plants with Bs as compared to the standard population. On the other hand, plants possessing $\mathrm{Bs}$ are at a distinct disadvantage at density 50 . This means that B plants are "superior" in terms of competitive ability and survival rate under conditions where selection pressure is least. This advantage is progressively lost as density increases, until at density 50 , their very existence in the population is threatened. With further increases in density, the proportion of B plants is no different from those in the standard. It would seem therefore that even under the extremely intense selection pressure encountered in the high densities, there is no differential mortality and both types of plants, Bs as well as 0 Bs have equal survival value.

The fact that more $B$ plants survive at density 5 is due to differential mortality affecting $0 \mathrm{~B}$ plants proportionately more than $\mathrm{B}$ plants. The percentage germination in the standard population at $25^{\circ} \mathrm{C}$ under laboratory conditions was 85 per cent, which is an indication of the real germination potential in the seed sample. The percentage survival at maturity at density 5 was only 51 per cent. Thus the effective mortality was of the order of 34 per cent compared to 82 per cent in density 150 .

The differential behaviour of plants in the two varieties is demonstrated more distinctly in fig. 3, showing the deviations of each density from the standard population. It is clear that in Experimental rye, the significant deviations in all densities except 5 were due to sharp decreases in B plants, particularly those from the $3 \mathrm{~B}$ and $4 \mathrm{~B}$ classes. In the Korean rye, the fluctuating deviations were caused mainly by varying numbers of $2 \mathrm{~B}$ plants. At density 5 , there was an excess of $2 \mathrm{~B}$ plants and a lack of $0 \mathrm{~B}$ plants and vice versa in density 50 . At high densities the deviations were extremely small and were insignificant.

\section{(v) Densities and $B$ frequencies: parents versus offspring}

Fifty seeds from the offspring from each density in each replicate were germinated on moist filter paper in petri dishes. All the seeds germinated 

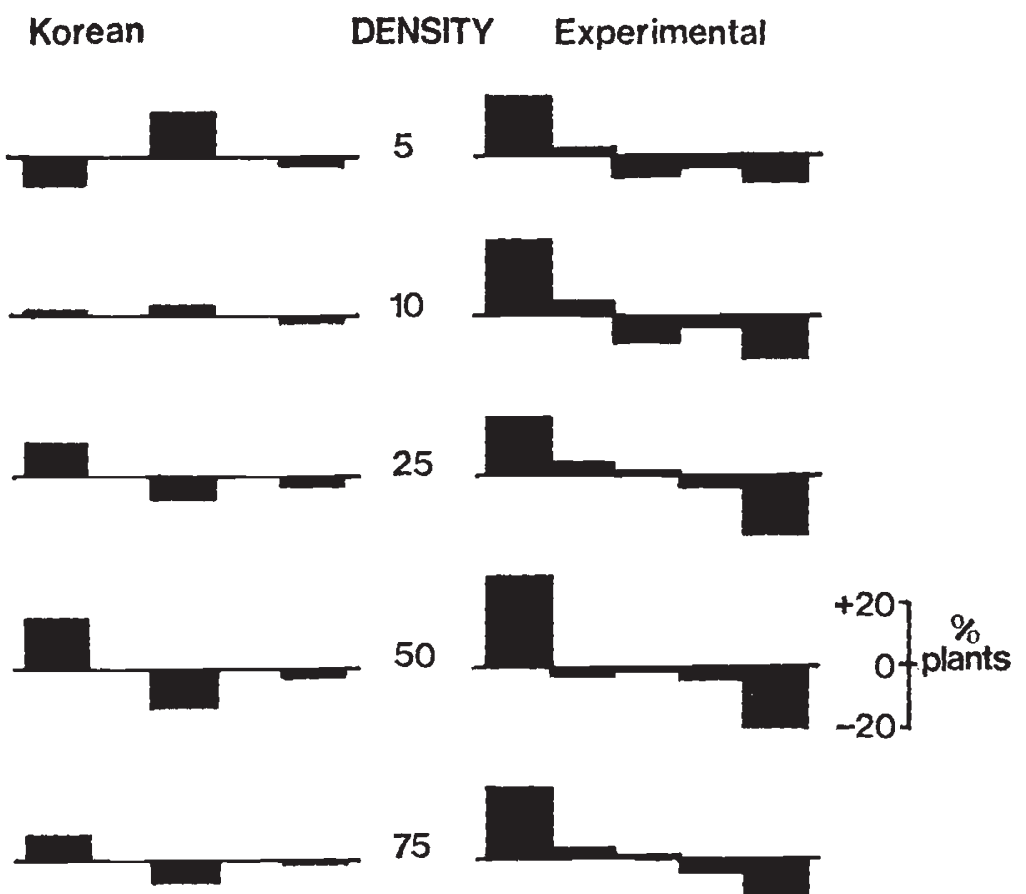

75
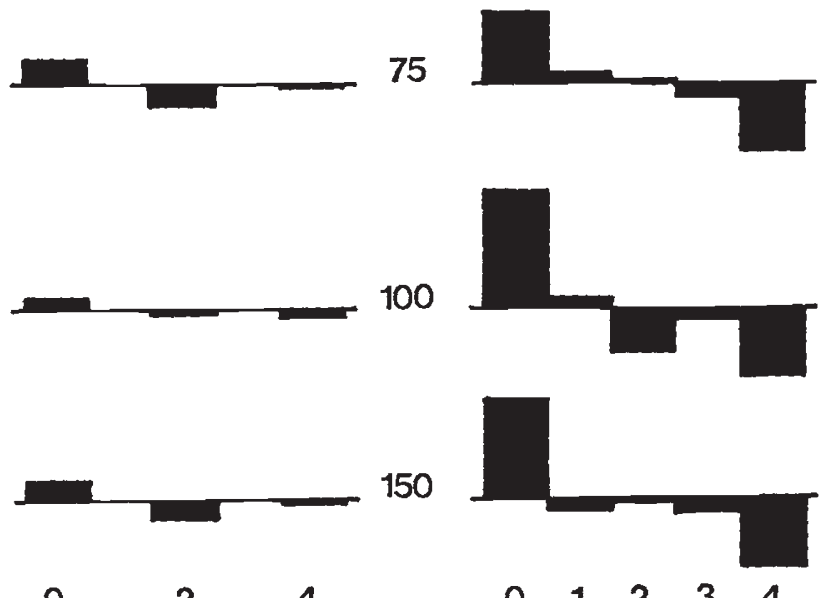

0

2

4

$\begin{array}{lllll}0 & 1 & 2 & 3 & 4\end{array}$

\section{B-CHROMOSOME CLASS}

Fig. 3.-Deviations from the standard rye population of plants grown at different densities (pooled over replicates).

were scored for the B chromosome content and the results appear in table 4 . An overall contingency chi-square analysis was performed between the offspring and parents in each variety separately to find out how the B chromosome distribution differs between generations and between densities. For this purpose, B classes were pooled, $2 \mathrm{~B}$ and $4 \mathrm{~B}$ in Korean; $1 \mathrm{~B}, 3 \mathrm{~B}$ and $4 \mathrm{~B}$ in the Experimental rye. This, again, is to ensure that as far as possible the smallest expectation is one (see Snedecor and Cochran, 1967, 
TABLE 4

$B$ chromosome distribution in the density experiments among progenies of the two rye varieties B-chromosome class

Density $\begin{array}{rlllllll} & & & & & & & \\ & 0 & 1 & 2 & 3 & 4 & 6 & 8\end{array}$ Total

(a) Experimental Rye

$\begin{array}{rrrrrrrrr}5 \mathrm{R} 1 & 18 & 2 & 15 & 2 & 5 & - & - & 42 \\ \text { R2 } & 15 & 0 & 18 & 1 & 4 & 1 & 1 & 40 \\ 10 \mathrm{R} 1 & 27 & 1 & 9 & 0 & 4 & - & - & 41 \\ \mathrm{R} 2 & 23 & 2 & 10 & 2 & 5 & - & - & 42 \\ 25 \mathrm{R} 1 & 29 & 1 & 9 & 0 & 2 & - & - & 41 \\ \text { R2 } & 21 & 0 & 19 & 1 & 3 & - & - & 44 \\ 50 \mathrm{R} 1 & 20 & 2 & 14 & 0 & 4 & - & - & 40 \\ \text { R2 } & 20 & 2 & 13 & 1 & 3 & 1 & - & 40 \\ 75 \mathrm{R} 1 & 22 & 1 & 9 & 2 & 6 & - & - & 40 \\ \text { R2 } & 25 & 0 & 6 & 1 & 4 & - & - & 36 \\ 100 \mathrm{R} 1 & 27 & 1 & 12 & 0 & 4 & - & - & 44 \\ \text { R2 } & 27 & 1 & 8 & 2 & 5 & - & - & 43 \\ 150 \mathrm{R} 1 & 31 & 1 & 7 & 1 & 2 & - & - & 42 \\ \text { R2 } & 25 & 2 & 9 & 0 & 5 & - & - & 41\end{array}$

(b) Korean Rye

$\begin{array}{rrrrrrrrr}5 \mathrm{R} 1 & 39 & - & 11 & - & - & - & - & 50 \\ \text { R2 } & 36 & - & 12 & - & 1 & - & - & 49 \\ 10 \mathrm{R} 1 & 35 & - & 14 & - & - & - & - & 49 \\ \text { R2 } & 39 & - & 11 & - & - & - & - & 50 \\ 25 \mathrm{R} 1 & 44 & - & 6 & - & - & - & - & 50 \\ \text { R2 } & 41 & - & 6 & - & 1 & - & - & 48 \\ 50 \mathrm{R} 1 & 41 & - & 7 & - & - & - & - & 48 \\ \text { R2 } & 43 & - & 5 & - & 1 & - & - & 49 \\ 75 \mathrm{R} 1 & 39 & - & 10 & - & - & - & - & 49 \\ \text { R2 } & 30 & - & 10 & - & 3 & - & - & 43 \\ 100 \mathrm{R} 1 & 35 & - & 14 & - & 1 & - & - & 50 \\ \text { R2 } & 35 & 1 & 12 & - & 2 & - & - & 50 \\ 150 \mathrm{R} 1 & 42 & - & 8 & - & - & - & - & 50 \\ \text { R2 } & 32 & - & 14 & - & 3 & - & - & 49\end{array}$

p. 235). The parents refer to plants that survived to maturity in the density experiments.

(a) Experimental rye. The contingency chi-square analysis between the parents and offspring of this variety, shows that: (i) there is no significant variation between replicates, (ii) the variation in the $\mathrm{B}$ chromosome distribution at different densities is significant ( $P=0.05-0.02)$, (iii) the interaction 
between densities and generations is not significant, (iv) the between generations component is significantly different $(P=0.02-0.01)$.

Two important conclusions emerge from the results above. First, the differences which existed in the B chromosome distribution in the parents have been carried over to the next generation. Secondly, the parents have given rise to progenies with significantly higher $B$ frequencies as well as more variation in $B$ numbers. It will be recalled that plants with more than 2 Bs were much reduced in numbers in the parents but in the offspring it was precisely plants from these classes that has led to the observed higher B frequencies. Nevertheless, the pattern in which the B frequencies are distributed throughout the densities in the offspring follows closely that of the parents (fig. $4 \mathrm{~B}$ ).
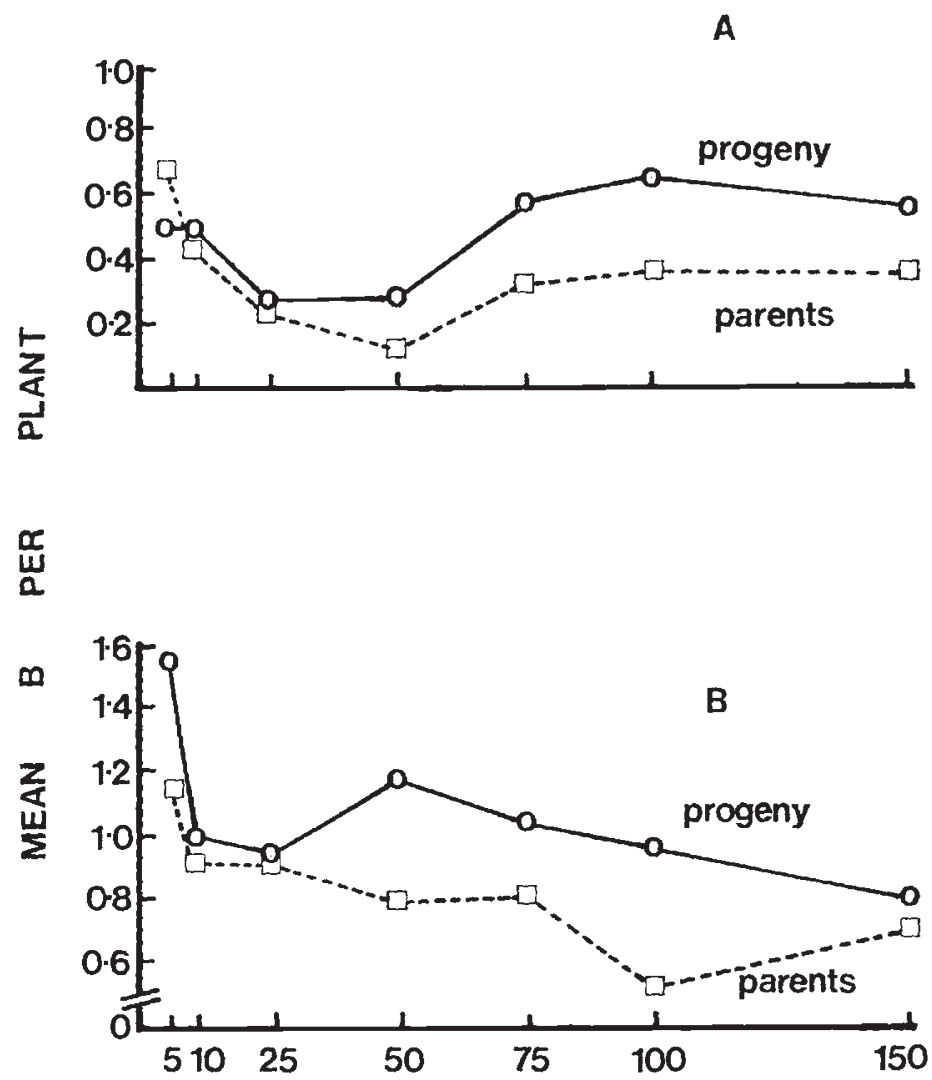

\section{DENSITY}

FrG. 4.-Relationship between mean $B$ frequency and sowing density in parents and offspring in (A) Korean and (B) Experimental rye.

(b) Korean rye. The results of the overall contingency chi-square analysis between the parents and offspring in this variety show no significant variation between replicates or in the interaction between generations and densities. However, there is a highly significant variation between densities $(P=$ $<0.001)$; the differences between densities in the parents are thus carried 
over to the next generation in this rye variety as well. The component between-generations was just not significant and this probably due to the combination of all B classes into one, the effect of which is to weaken the sensitivity of the test (see Snedecor and Cochran, 1967, p. 235). That the offspring indeed have a higher B frequency can be clearly seen in table 5

TABLE 5

Overall distribution of $B$ chromosome frequencies in the standard populations, parents and offspring B chromosome class

\begin{tabular}{|c|c|c|c|c|c|c|c|}
\hline $\begin{array}{l}\text { Population } \\
\text { (a) Experimental rye }\end{array}$ & 0 & 1 & 2 & 3 & $4+>4$ & Total & $\begin{array}{l}\text { Mean } B \\
\text { per plan }\end{array}$ \\
\hline Standard & 102 & 9 & 110 & 14 & 65 & 300 & $1 \cdot 77$ \\
\hline Parents & 166 & 14 & 90 & 0 & 10 & 280 & 0.84 \\
\hline Offspring & 330 & 16 & 158 & 13 & 59 & 576 & $1 \cdot 05$ \\
\hline \multicolumn{8}{|l|}{ (b) Korean rye } \\
\hline Standard & 170 & & 42 & & 7 & 219 & $0 \cdot 51$ \\
\hline Parents & 289 & & 59 & & 2 & 350 & $0 \cdot 36$ \\
\hline Offspring & 531 & & 140 & & 13 & 684 & 0.49 \\
\hline
\end{tabular}

and fig. 4A. This figure also shows the striking similarities in the B chromosome distribution between the two generations. As in the Experimental variety, the $\mathrm{B}$ chromosome composition of the parents profoundly influence those of the progenies.

(vi) Comparison of $B$ frequencies between parents, offspring, and stanalard population

One way of examining the differences or similarities between the two generations in each rye variety is by totalling the frequencies in each B class for all densities and comparing their total values with each other and with those of the standard. For convenience, the overall distribution in the parents or offspring, will be referred to as "populations" and these, including the standard, are given in table 5 .

A contingency chi-square analysis performed separately for each variety shows that: (i) in Experimental rye, the chi-square value of 89.53 is highly significant $(\mathrm{P}<0.001)$, (ii) there are no significant variations among the three "populations" of Korean rye $\left.\left(\chi^{2}{ }_{4}\right)=7 \cdot 82 ; \mathrm{P}=0.05-0 \cdot 10\right)$.

In Experimental rye all the combinations tested were found to be significantly different $(\mathrm{P}<0.001)$ indicating that all three "populations" differ from one another. However, in the Korean variety, only the deviations between parents and standard are significantly so $(\mathbf{P}<0 \cdot 05)$. The variation between parents and offspring are again just not significant. The interesting feature in this variety is that the frequency of plants with $\mathrm{Bs}$ in the progenies has reached that in the standard population $(P=0.50)$.

\section{Discussion}

The B chromosome polymorphism in rye can be altered by subjecting experimental populations to varying degrees of selection pressure. Adjustments in mean B frequency, which accompany the different levels of 
arbitrarily selected population densities, provide evidence for differential fitness of the $0 \mathrm{~B}$ and different plus-B classes of plants. Comparisons between two different populations, and an extension of the analysis to include progenies as well, provide additional information on the relative performance of Bs of differing origin and of carry-over effects to the next generation. This latter consideration is of some importance because the $B$ chromosomes in rye are inherited in a non-Mendelian fashion and have the capability to increase in numbers from one generation to the next.

The Experimental population used here is of hybrid origin; it is also a "young" population and has no history of natural selection and adaption. B chromosome-carrying individuals are of inferior fitness, compared with the $0 \mathrm{~B}$ types, and the mean B frequency per plant declines steadily with increasing density and mortality. It is of interest to note, however, that the odd-numbered and high-numbered B-combinations are particularly sensitive to increased stress, and to recall that the mechanism of heredity of $B$ chromosomes is biased in favour of the even-numbered combinations (see Jones and Rees, 1969). Furthermore, it is important to note that the parent plants used in the experiment, with an overall mean $B$ frequency of 0.8 gave rise to progenies with significantly higher mean $B$ frequencies (1.05) as well as more variation in B numbers. The reduced fitness of the Bcarrying individuals operative in one generation can be compensated for by the effectiveness of the accumulation mechanism which boosts the number, and range of $B$ types, in the following generation.

The Korean variety originates from a natural population. Its B chromosomes have a history of exposure to the forces of natural selection and have evolved in close relationship with the A chromosome complement. The inheritance of the $\mathrm{Bs}$ in this material is more regular and stable than that of the Experimental population. Odd-numbered B combinations are completely lacking and plants with more than $2 \mathrm{Bs}$ are also quite infrequent. The relationship between mean B frequency and density is complex, as we have shown, but what is most striking about this population is the fact that at the lowest density of five plants per pot the mean B frequency $(0.68)$ is significantly higher than that of the standard population $(0.5)$ from which the seeds were taken. Even at this relatively low density of planting the mortality rate is considerable, with only half the plants surviving to maturity. At the highest density of 150 plants per pot, and survival down to just over 3.0 per cent, there is no significant deviation of B chromosome distribution from that of the standard population. In some competitive situations the B chromosome individuals of this population, in contrast to the unadapted Experimental population, have fitness values superior to those of the $0 \mathrm{~B}$ plants. The mean $\mathrm{B}$ frequency in progenies is again higher than that of the parents, but not significantly so, and approaches the level of that found in the standard Korean population.

It is useful to compare the outcome of this experiment, for the Korean rye, with that of Hutchinson (1975) in which the B chromosome types of a Japanese strain were of inferior fitness over a similar range of density conditions. Hutchinson's Japanese population and the Korean population used in this investigation have both been maintained as open pollinating populations of spaced plants, at Aberystwyth, for a number of generations. The two populations have consistently displayed opposing trends in their B frequency fluctuations over the generations. In the Japanese material the 
percentage of plants with Bs has declined steadily from 45 per cent down to 28 per cent over five generations, while in the Korean stock the frequency has risen from 2 per cent to over 30 per cent in the same period. The Japanese and Korean populations are not strictly comparable, in the way the Korean and Experimental ones are, but there nevertheless are grounds for concluding that $\mathrm{B}$ chromosomes of different origin and habitat do differ in their reproductive and physiological fitness.

The differential mortality which gives rise to changes in $B$ frequency and distribution at the different density conditions may arise, as we have indicated, partly at the time of germination and partly at some later stage of development. We are not in a position to say anything about differential selection of the various $B$ types at germination time, other than to reaffirm that there is very high mortality at this critical stage of the developmental sequence.

Finally, we draw attention to, and refute yet again, the recurring argument (see Rhoades and Dempsey, 1972) that B chromosomes have no adaptive significance in the genetic system, and that they are maintained in populations solely on account of their potent and effective accumulation mechanisms. The results present here, as with those in Lolium (Teoh, Rees and Hutchinson, 1976) run quite counter to this point of view.

\section{REFERENGES}

hutchinson, J. 1975. Selection of B chromosomes in Secale cereale and Lolium perenne. Heredity, 34, 39-52.

JONES, R. N. 1975. B-chromosome systems in flowering plants and animal species. International Review of Cytology, 40, 1-100.

JONES, R. N., AND REES, H. 1967. Genotypic control of chromosome behaviour in rye. XI. The influence of B-chromosomes on meiosis. Heredity, 22, 333-347.

JONES, R. N., AND REES, H. 1968. The influence of B-chromosomes upon the nuclear phenotype in rye. Chromosoma, 24, 158-176.

JONES, R. N., AND REES, H. 1969. An anomalous variation due to $\mathrm{B}$ chromosomes in rye. Heredity, 24, 265-271.

KISHIKAWA, H. 1965. Cytogenetic studies of B-chromosomes in rye. Secale cereale L., in Japan. Agricultural Bulletin of Saga University, 21, 1-81.

LEE, W. J., AND MIN, B. R. 1965. On accessory chromosomes in Secale cereale. 1. Frequency and geographical distribution of plants with accessory chromosomes in Korea. Korean Fournal of Botany, $8,1-6$.

REES, H., AND hUTChINSON, J. 1973. Nuclear DNA variation due to B chromosomes. Cold Spring Harbor Symposium on Quantitative Biology, 38, 175-182.

RHOADES, M. M., AND DEMPSEY, E. 1972. On the mechanism of chromatin loss induced by the B-chromosome of maize. Genetics, 71, 73-96.

SNEDECOR, G. W., AND Cochran, w. G. 1967. Statistical Methods. Iowa State University Press. TEOH, S. B., REES, H., AND HUTCHINSON, J. 1976. B-chromosomes selection in Lolium. Heredity, $37,207-213$.

ZEČEVIĆ, L., AND PAUN Ović, D. 1967. B-chromosome frequency in Yugoslav rye populations. Biologia Plantarum, 9, 205-211. 